\title{
Correlation of fine needle aspiration cytology with histopathology findings in cases of thyroid lesions in Bir Hospital
}

\section{P B Thapa, ${ }^{1}$ D Shrestha, ${ }^{2}$ J P Pradhananga ${ }^{3}$}

${ }^{1}$ Tutor, ${ }^{2}$ Associate Professor, ${ }^{3}$ Medical Officer, Department of ENT and Head and Neck Surgery, National Academy of Medical Sciences,Bir Hospital ,Kathmandu

\section{Abstract}

\section{Aims}

To correlate the findings of fine needle aspiration cytology (FNAC) with the histopathology( HPE) of the excised nodule or specimen and to assess the accuracy and efficacy of FNAC in the diagnosis of the thyroid nodules.

\section{Materials and methods}

This is a prospective study conducted at the Department of Ear Nose Throat (ENT) \& Head \& NecK Surgery( HNS), National Academy of Medical Sciences, Bir Hospital, Kathmandu from $2^{\text {nd }}$ January 2009 to $29^{\text {th }}$ December 2011. One hundred patients with thyroid nodule were included in the study.

\section{Results}

Out of 100 patients 77 were females and 23 males. The age ranged from 11-60 years. Statistical analysis of results for Benign Thyroid lesion showed $98.6 \%$ sensitivity, $75 \%$ specificity. Likewise, results for Malignant thyroid lesions showed $75 \%$ sensitivity, $98.6 \%$ specificity .

\section{Conclusion}

FNAC has high accuracy in the diagnostic evaluation of thyroid lesions.

\section{Key words: Thyroid, FNAC, Histopathology.}

\section{Introduction}

Thyroid nodules are very common clinical entities. Clinical palpation suggests a prevalence of thyroid nodules of 4 to $7 \%$ in adults and $0.2 \%$ to $1.2 \%$ in

Correspondence: Dr. P.B. Thapa E-mail: children. ${ }^{1-4}$ Ultrasonography studies revealed the prevalence of thyroid nodule in the general population between $19-46 \% .^{5-7}$

Regardless of the incidence of thyroid nodules, the critical question remains whether a detected nodule is 
malignant. Many advances in diagnostic capabilities have helped clinicians to identify malignant nodules. FNAC is a well-established technique for preoperative investigations of thyroid nodule. Practice guidelines set by the American Thyroid Association (ATA) and National Comprehensive Cancer Network( NCCN); state that FNA should be used as the initial diagnostic test because of its superior diagnostic reliability and cost effectiveness before both thyroid scintigraphy and ultrasonography. ${ }^{8}$ As FNAC distinguishes between benign and malignant lesions quite effectively, it is the pre-operative screening method of choice worldwide. ${ }^{9-11}$

\section{Aims and objectives}

The aim of this study was to correlate the findings of fine needle aspiration cytology with the histopathology of the excised nodule or specimen and to assess the accuracy and efficacy of FNAC in the diagnosis of the thyroid nodules and to compare its sensitivity and specificity with histopathology.

\section{Materials and methods}

This is a prospective study conducted at the Department of ENT \& HNS, National Academy of Medical Sciences, Bir Hospital, Kathmandu from $2^{\text {nd }}$ January 2009 to $29^{\text {th }}$ December 2011. One hundred patients with thyroid nodule were included in the study and evaluated through detailed history, general physical examination, ENT and neck examination. Findings were noted on pre-designed performa. After ultrosonographic studies, Pathologist performed FNA in all cases and cytological diagnosis was made. Inclusion criteria included clinically detected thyroid nodule and patients with normal thyroid function test. Patients with abnormal thyroid function test and who were unfit for surgery were excluded.

All patients were admitted to our department. Investigations done were ultrasound, complete blood count, Blood sugar, renal function test, FNAC, thyroid function profile and chest and neck X-ray in all patients. CT scans were done only in selected cases. Thyroid scan was not done due to unavailability of such facility in our institute during the time of study. Written and informed consent for surgery was taken. All the excised thyroid specimen were sent for histopathology examination at the same Pathology department. SPSS10 was used for data analysis. Frequencies and percentages were computed to present FNAC and HPE findings. Taking histopathology as gold standard criteria, sensitivity, specificity and accuracy of FNAC, relative to the final histological diagnosis were analyzed by SPSS software, using the following formulae:
- $\quad$ True positive (TP):

- $\quad$ False positive (FP):

- $\quad$ True negative $(\mathrm{TN})$ :

- $\quad$ False negative $(\mathrm{FN})$ :

- $\quad$ Sensitivity (S):

- $\quad$ Specificity (Sp):

- $\quad$ Diagnostic accuracy (DA):
Positive result in FNA, and confirmed in the histological study.

Positive result in FNA, but not confirmed in the histological study.

Negative result in FNA, and no pathology in histological study.

Negative result in the FNA, but detected in the histological study.

Proportion of patients with associated disease and positive in the FNAC, $\mathrm{S}=\mathrm{TP} /(\mathrm{TP}+\mathrm{FN})$.

Proportion of patients without associated disease and with a negative result in the FNAC, $\mathrm{Sp}=\mathrm{TN} /(\mathrm{TN}+\mathrm{FP})$

Proportion of patients diagnosed correctly by the diagnostic test. $\mathrm{DA}=(\mathrm{TP}+\mathrm{TN}) /(\mathrm{FP}+\mathrm{FN}+\mathrm{TP}+\mathrm{TN})$ 
P B Thapa et al, Correlation of fine needle aspiration cytology.......

\section{Results}

Out of 100 patients 77 were females and 23 males with F: M ratio of 3:1 (Chart 1). The age ranged from 11-60 years with the mean age of 38.5 years (Chart 2). The definitive histopathology study revealed 72 cases as benign and 28 malignant. On cytology 78 cases were benign, of which 72 cases were correctly diagnosed as benign, and 1 was false negative (Chart

\section{Chart 1: Sex Distribution}

3). In 28 malignant cases 21 were diagnosed correctly on cytology as well as histopathology report (21 cases were true positive). 1 case of false positive was detected in our study (Chart 4). Statistical analysis of results for Benign Thyroid lesion showed 98.6\% sensitivity, $75 \%$ specificity and with overall accuracy of $92 \%$ of procedure (Chart 5). Likewise, results for Malignant thyroid lesions showed $75 \%$ sensitivity, 98.6\% specificity and with $92 \%$ accuracy (Chart 6).

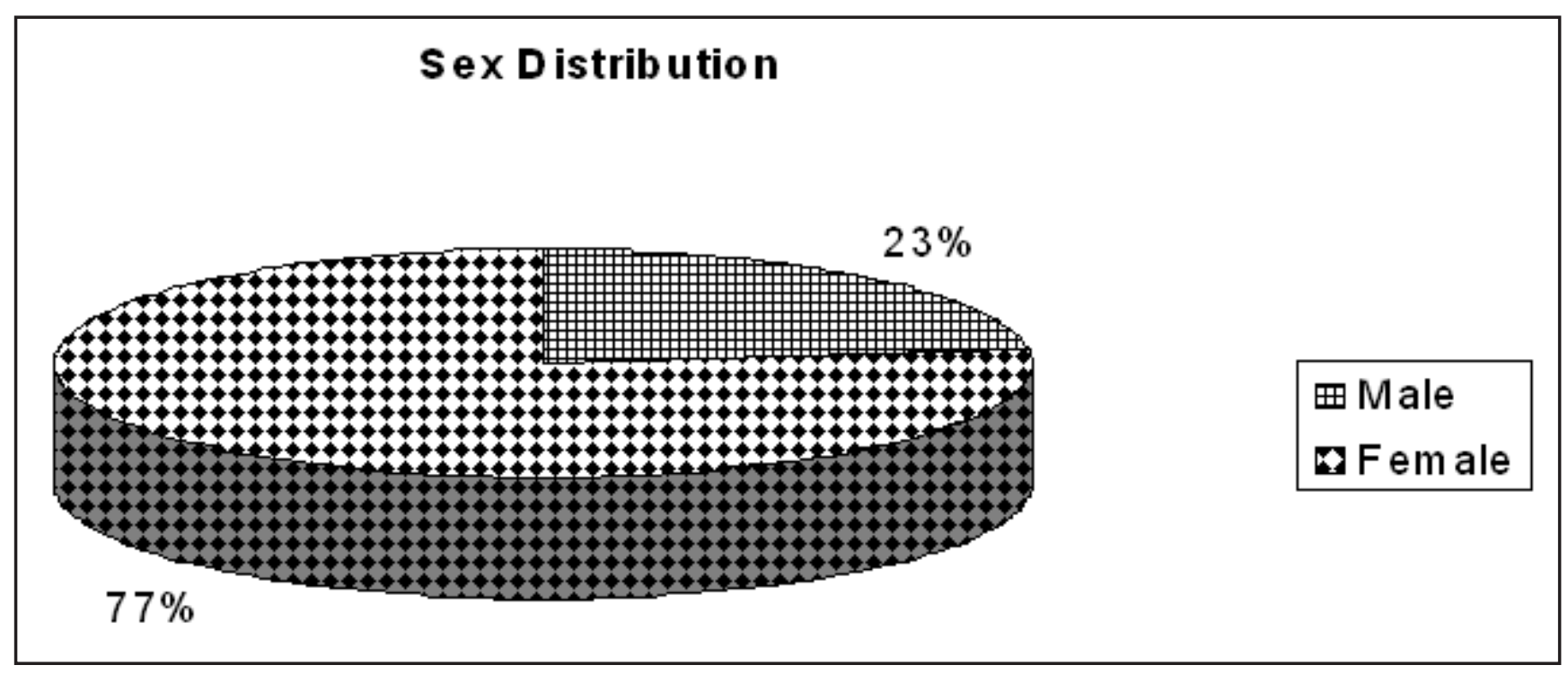

Chart 2: Age:Sex Ration

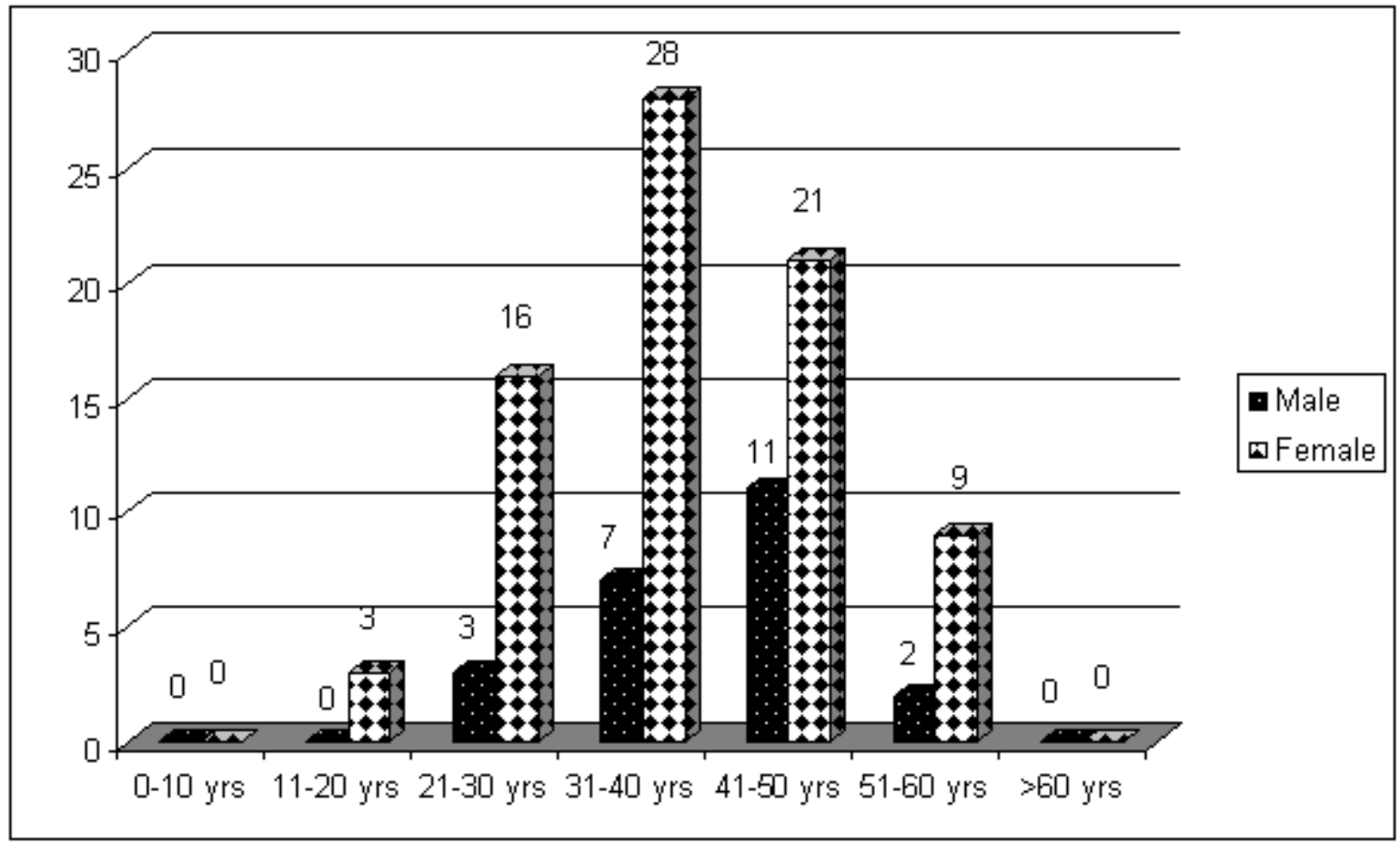




\section{Chart 3: FNAC Finding}

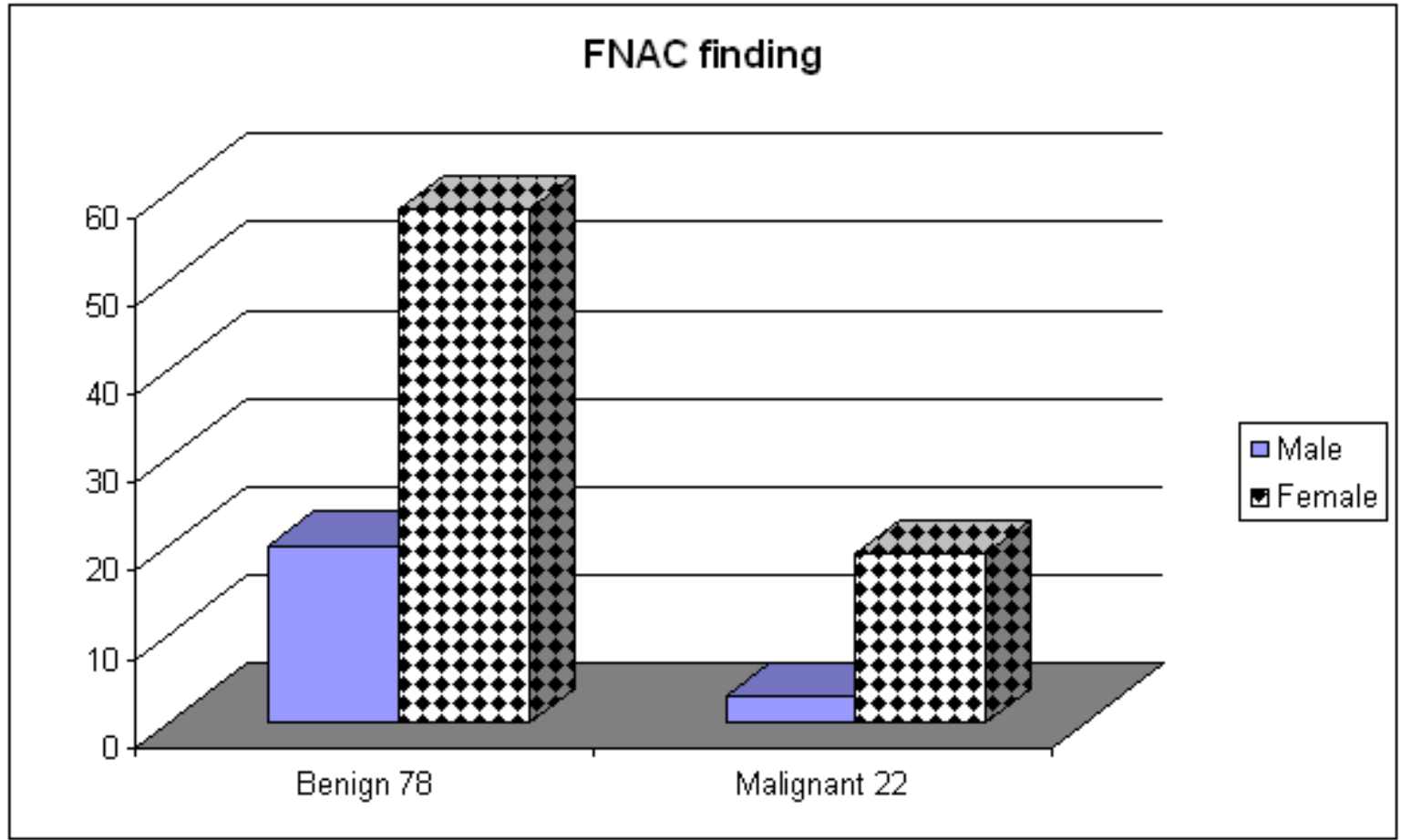

Chart 4: HPE Finding

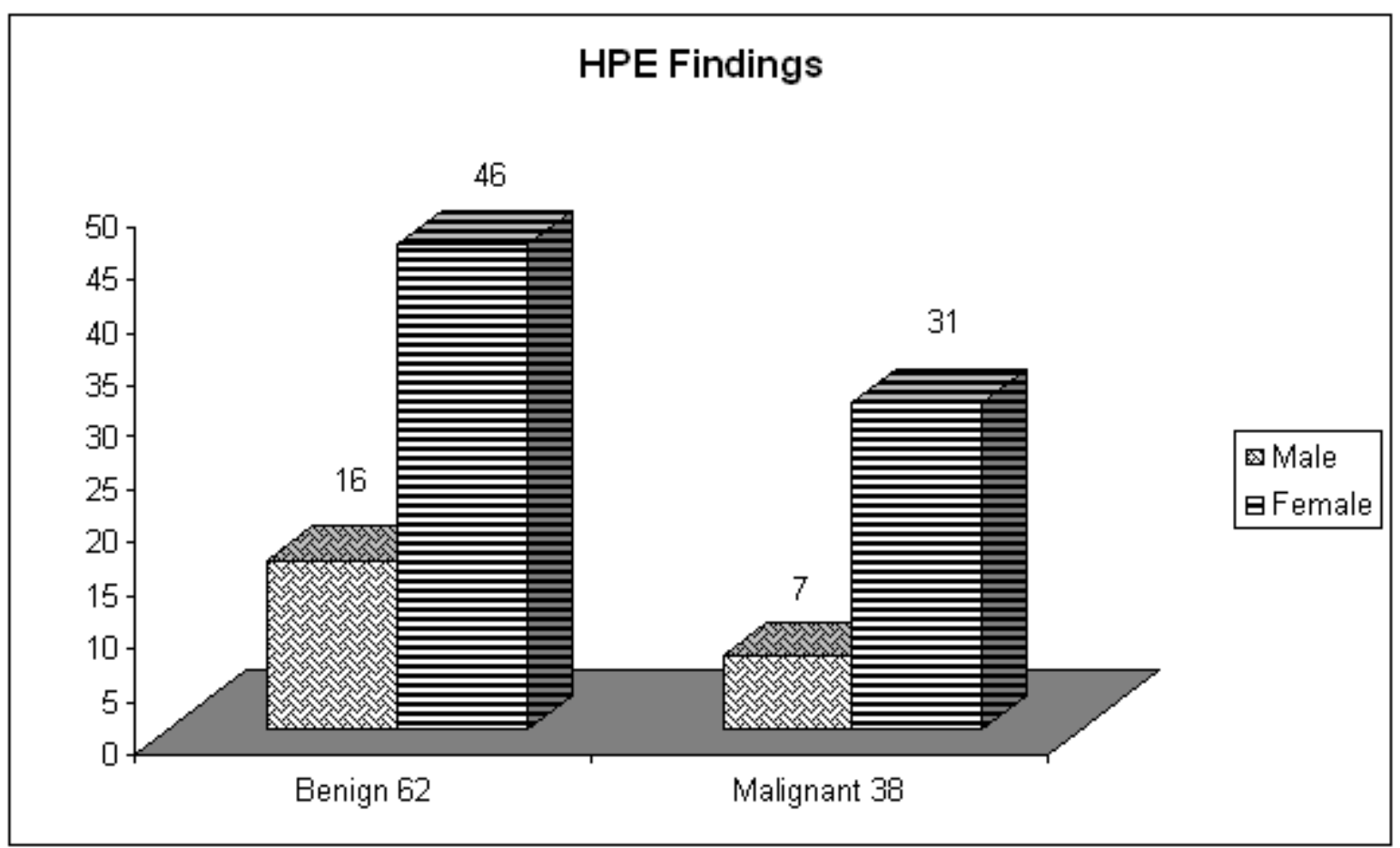


P B Thapa et al, Correlation of fine needle aspiration cytology.

Chart 5 : Correlation for benign lesions:

\section{Correlation}

\begin{tabular}{llc}
\hline True Positive (TP) & FNAC + HPE + & 71 \\
\hline False Positive (FP) & FNAC + HPE - & 07 \\
True Negative (TN) & FNAC - HPE - & 21 \\
False Negative (FN) & FNAC - HPE + & 01 \\
Total & & 100 \\
Sensitivity (S) & TP/(TP+FN) X 100 & $98.6 \%$ \\
Specificity (Sp) & TN/(TN+FP) X 100 & $75 \%$ \\
\hline
\end{tabular}

\section{Chart 6 : Correlation for malignant lesions:}

\section{Correlation}

\begin{tabular}{llc}
\hline True Positive (TP) & FNAC + HPE + & 21 \\
\hline False Positive (FP) & FNAC + HPE - & 01 \\
True Negative (TN) & FNAC - HPE - & 71 \\
False Negative (FN) & FNAC - HPE + & 07 \\
Total & & 100 \\
Sensitivity (S) & TP/(TP+FN) X 100 & $75 \%$ \\
Specificity (Sp) & TN/(TN+FP) X 100 & $98.6 \%$ \\
Diagnostic Accuracy (DA) & $(\mathrm{TP}+\mathrm{TN}) /(\mathrm{TP}+\mathrm{FP}+\mathrm{TN}+\mathrm{FN}) \mathrm{X} 100$ & $92 \%$ \\
\hline
\end{tabular}

\section{Discussion}

FNAC contributes significantly to the pre operative investigation in patients with a solitary or dominant thyroid nodule but despite its well recognized value there are limitations to the technique. The aim of this study was to evaluate the diagnostic accuracy in 100 patients with thyroid lesions submitted to FNAC and for biopsy after surgery. The false negative FNAC results may occur because of sampling error or misinterpretation of cytology, and are of great concern because they indicate the potential to miss malignant lesion. ${ }^{12}$ Most authorities agree that the true false negative rate is below $5 \%$.
False negative FNA cytology results occurred in 7 (7 $\%$ ) of our patients. This is also consistent with recent reports in the literature that suggest a false negative rate of $2 \%$ to $7 \% .^{14-19} \mathrm{~A}$ false positive cytology result may in retrospect have resulted in surgical over treatment for an individual patient. False positive FNA cytology results are uncommon and were found in only $1(1 \%)$ patient in this series. This finding is consistent with other recent reports that cited an incidence of false positive FNA cytology results ranging from $0 \%$ to $9 \% .^{14-19}$ 
The sensitivity of thyroid FNAC range from $65 \%$ to $99 \%$ and its specificity from $72 \%$ to $100 \% .20-24$ In this study, the sensitivity for cytological diagnosis of neoplasia was $98.6 \%$, specificity of $75 \%$ and diagnostic accuracy of $92 \%$ which is similar to the experience of others. ${ }^{20-24}$ Ikram et al has reported sensitivity and specificity for malignancy as $100 \%$ which is slightly higher than our results as they do not have falsepositive results in their study due to small number of patients. ${ }^{25}$ Our study also testifies the results of previously done study at Aga Khan University by Afroze N et al, where they have reported sensitivity of $61.9 \%$, the specificity of $99.31 \%$ and accuracy index of $94.58 \%$. This is slightly different then our results and this may be due to the fact that they had considered suspicious cases alternatively as positives and negatives. ${ }^{26}$ Our results also coincide with results of Safirullah et al, where they have reported a sensitivity of $94.2 \% .{ }^{27}$ Inadequate FNA specimen may be results of inadequate sampling or focal lesion.

\section{Conclusion}

The assessment of the patient with a thyroid lesion includes the triple modalities of clinical examination, cytology and imaging investigations. The result of thyroid aspiration cytology is therefore only one factor governing the management decision. Indeterminate FNAC results and cytodiagnostic errors are unavoidable due to overlapping cytological features particularly among hyperplastic adenomatoid nodules, follicular neoplasms and follicular variants of papillary carcinomas. Ongoing correlation of cytology and histology is an important quality assurance measure and it allows laboratories to calculate their false positive and false negative rates.
We conclude that FNAC is an invaluable and minimally invasive procedure for pre operative assessment of patients with a thyroid nodule. FNAC has high accuracy in the diagnostic evaluation of thyroid lesions.

\section{References}

1. E. C. Ridgway, "Clinical evaluation of solitary thyroid nodules," in The Thyroid: A Fundamental and Clinical Text, G. B. Lippincott, Philadelphia, a, USA, 1986; 1377-85.

2. Vander JB, Gaston EA Dawber TR. The significance of nontoxic thyroid nodule: final report of a 15 year study of the incidence of thyroid malignancy. Ann Int Med 1968;69:537-40.

3. Gharib $\mathrm{H}$. fine needle aspiration biopsy of thyroid: An appraisal. Ann Int Med 1993; 118: 282-9.

4. Rojeski MT, Gharib H. Nodular thyroid disease: evaluation and management. N Eng J Med 1985; 313: 428-36.

5. Brander A, Viikinkoski P, Nickels J et al. Thyroid gland: US screening in a random adult population. Radiology 1995;181: 683-7.

6. Wienke JR, Chong WK, Fielding JR et al. Sonographic features of benign thyroid nodules. Journal of Ultrasound Medicine 2003; 22: 1027-31.

7. Screaton NJ, Berman L \& Grant JW. US-guided core-needle biopsy of thyroid gland. Radiology 2003; 226: 827-32.

8. H. thyroid fine Needle aspiration (FNA) and cytology. Thyroid 2003;13: 80-6.

9. Tyler DS, Shaha AR, Udelsman RA, et al. thyroid cancer; 1999 update. Ann Surgoncol 2000;376-98.

10. Wong CK, Wheeler MH. Thyroid nodules: rational management. World J Surg 200; 24: 934-41. 
P B Thapa et al, Correlation of fine needle aspiration cytology.

11. Roman SA. Endocrine tumors: Evaluation of thyroid nodule. Curropinoncol 2003; 15: 66-70.

12. Hall TL, Layfield LJ, Philippe A, et al. Source of diagnostic error in the fine needle aspiration of the thyroid. Cancer 1989; 63:718-25.

13. Gharib H, Goellner JR. Fine needle aspiration biopsy of the thyroid: an appraisal. Ann Intern med 1993; 118: 282-9.

14. Goldstein RE, Netterville JL, Burkey B,et al. Implications of follicular neoplasms, atypia and lesions suspicious for malignancy diagnosed by fine needle aspiration of thyroid nodules. Ann Surg 2002; 235: 656-64.

15. Pahavasit A, Thompson GB, hay ID et al. follicular and hurthle cell thyroid neoplasma. Is frozen section evaluation worthwhile Ann Surg 1997; 132: 647-80.

16. Richards MZ, Chisholm R, Bruder JM, Strodel WE. Is thyroid frogen section too much for too little? Ann J Surgery 2002; 184: 510-14.

17. Udelsman R, Westra WH, Donovan PI et al. randomized prospective evaluation of frozen section analysis for follicular neoplasms of the thyroid. Ann Surg 2001; 233: 716-20.

18. Layfield LJ Reichman A, Bottlesk, Guiliano A. clinical determinants for the management of thyroid nodules by fine needle aspiration cytology. Arch otolaryngoi head neck surgery 1992: 182: 717-21.

19. Liel Y, Ariad S, Barchana M. Long term follow up of patients with initially benign thyroid fine needle aspiration. Thyroid 2001; 11: 775-8.
20. Caraway NP, Sneige N, Samaan N. Diagnostic pitfalls in thyroid fine needle aspiration: a review of 394 cases. DiagnCytopatho 1993; 9: 345-50.

21. Cruso D, Muzzaferri EL. Fine needle aspiration biopsy in the management of thyroid nodules. Endocrinologist 1991; 1: 1194-202.

22. Muzzaferri EL. Management of a Solitary thyroid nodule. $N$ Eng J Med 1993: 328: 553-9.

23. Ridgway CE. Clinical review 30: Clinicians evaluation of a solitary thyroid nodule. $J$ clinEndocrinolmetab 1992; 74: 231-5.

24. Chang H.Y, Lin J-D, Chen JF, et al Corelation of fine needle aspiration cytology and frozen section biopsies in the diagnosis of thyroid nodules. $J$ CeinPathol 1997; 50: 1005-9.

25. Ikram M, Hyder J, Muzaffar S et al. Fine Needle Aspiration cytology (FNAC) in the management of thyroid pathology - the Aga Khan University Hospital experience. J Pak Med Assoc 1999; 49(6):133-5.

26. Afroze N, Kayani N, Hasan SH. Role of Fine needle aspiration cytology in the diagnosis of palpable thyroid lesions. Indian $J$ PatholMicrobiol 2002; 45(3):241-6.

27. Safirullah, NaeemMumtaz, Akbar Khan. Role of Fine Needle Aspiration Cytology (FNAC) in the diagnosis of Thyroid swellings. J Postgrad Med Inst 2004; 18(2): 196- 201. 